\title{
Retrospective Study of Fatal Dengue Hemorrhagic Fever in Lahore City
}

\author{
Article by Samra Ashraf \\ Master in Nursing Texila American University, Pakistan \\ E-mail: Samrashrf@yahoo.com
}

\section{List of Abbreviations}

DHF Dengue Hemorrhagic Fever

AST Aspartate Aminotransferase

ALT Alanine Aminotransferase

WHO World Health Organization

LFT's Liver Functioning Tests

RFT's Renal Functioning Tests

\section{Introduction}

Dengue fever is one of the most common mosquito-borne viral diseases of human beings. It has become a major reason for public health concern internationally over the recent years because of disease morbidity and mortality. Globally around 2.5 billion people are living in areas where dengue viruses can be transmitted. Spread of mosquito vectors \& viruses in geographical distribution are two main reasons of rise in incidence and prevalence of dengue fever \& appearance of dengue hemorrhagic cases. Urban areas of the tropics have been identified to be highly endemic. According to estimates made by WHO around 50-100 million infections of dengue are prevalent every year globally. (Deen et al. 2006) In Pakistan first dengue outbreak was reported in Karachi in 1994 as environmental conditions are conducive to Aedes mosquito breeding. Economic and security related migration introduced virus to Lahore as well. According to Punjab Health Department 590339 suspected cases were reported in Lahore \& 21685 confirmed by serology. It has been observed that 5-10\% of these cases develop DHF.(Mahmood et al. 2013)

Dengue is mainly transmitted by mosquito vector i.e. Aedesaegypti and can also be transmitted by A. albopictus to a lesser extent. Virus that causes dengue has four different types that are closely related to each other. Infected female mosquitoes transmit this virus to human beings through bite. An infected mosquito can transmit this virus to humans for the rest of its life. Symptoms of dengue range from very mild fever to very high fever including intense headache, retro-orbital pain, muscular and joint pain, and rashes. There is no vaccine or any specific medicine to treat dengue. Patients having dengue fever are advised to take rest and drink ample fluids. They are advised to use paracetamol in order to reduce high grade fever or visit the physician if fever persists. Recovery from infection by one provides lifelong immunity against that serotype but confers only partial and transient protection against subsequent infection by the other three. There have been enough proofs showing that subsequent infection increases the risk of severity of disease which can result in DHF (WHO).

Leaking of plasma, fluid accumulation, respiratory distress, and intense bleeding and organ impairment makes severe dengue a fatal complication. Warning signs includes decrease in temperature (below $38^{\circ} \mathrm{C} / 100^{\circ} \mathrm{F}$ ), severe abdominal pain, rapid breathing, bleeding gums, malaise, and restlessness, continuous vomiting and hematemesis. These can occur three to seven days after first symptom recognition. In order to prevent complications and minimize the risk of death adequate and timely health care is required in next 1-2 critical days.(Halstead 1980)

In 1950s when dengue epidemics occurred in the Philippines and Thailand then Dengue hemorrhagic fever was first identified. Till 1970 nine countries had encountered epidemic 
Texila International Journal of Public Health

Volume 4, Issue 4, Dec 2016

DHF and this number has increased more than four times and keeps on rising. Today rising number of DHF cases are causing increased dengue outbreaks in the Americas, and in Asia, where all four dengue viruses are endemic. DHF has turn out to be a prominent reason of hospitalization and demise among kids in several states. In Asia, widespread DHF has enhanced geologically from Southeast Asian regions to west China. Various regional states of the South and Central Pacific have encountered significant or slight DHF outbreaks. In previous twenty years deterrence and management has come to be more immediate with the escalating geographical spread of dengue and dengue hemorrhagic fever and higher ailment occurrence (Gubler 2002).

In the absence of bleeding or organ manifestation, DHF is medically challenging to diagnose, and the numerous etiologic agents can barely be distinguished by clinical tests. The specified diagnosis of DHF depends mainly on laboratory testing.(Drosten et al., 2002)

\section{Review of literature}

\section{Dengue hemorrhagic fever}

(Gubler, 2002) DHF largely an illness of kids below fifteen years of age, but can occur among elderly as well. It is recognized by abrupt beginning of fever, which generally continues for two to seven days, and a wide range of nonspecific signs and symptoms. Throughout the critical period of disease, it is challenging to differentiate DHF from dengue fever and other illnesses found in tropical regions. The differential diagnosis through the severe stage of illness should include influenza, typhoid, rubella, malaria, measles other viral hemorrhagic fevers, and number of other ailments that can be found in the acute phase as a broad-spectrum virus-related disorder. There is no pathognomonic sign or symptom for DHF during the acute stage; contrarily when fever disappears, typical appearances of plasma seepage starts, causing exact clinical diagnosis feasible among several patients.

\section{History}

(Guzman et al. 1999) Dengue hemorrhagic fever in adults in outbreak pattern was noticed for the very first time through the Cuban DHF epidemic of 1981. Records of DHF in people elderly than 15 years have steadily elevated, primarily in the American area. Throughout the 1997 Cuban DHF outbreak, 205 DHF cases were noticed, all with serologic or virologic evidence. Of these, 12 affected individuals deceased. The 12 lethal cases were categorized as DHF in accordance to the Guidelines for the Prevention and Control of Dengue and Dengue Hemorrhagic Fever in the American Area.

\section{Geographical distribution}

(Pinheiro et al,. 1997) Around two-thirds of the world's inhabitants reside in places swarmed with dengue vectors, primarily Aedesaegypti. All of the four dengue viruses are distributed, often concurrently, in most of these regions. It is approximated that around 80 million individuals turn out to be attacked yearly despite the fact that significant underreporting causes the alert of much lesser statistics. Presently dengue is endemic in all major regions other than Europe and outbreak dengue hemorrhagic fever (DHF) develops in Asia. The occurrence of DHF is much greater in the Asian countries than in other areas.

\section{Dengue in pakistan}

(Khan et al. 2013) Dengue fever appeared to be a significant wellbeing issue in Southeast Asia particularly Pakistan \& until any particular vaccination or any antiviral substance turn out to be accessible, healthcare provider need to be dependent to quick recognition for hazard variables affiliated to producing Dengue fever complications; simply identical to alert characteristics described via WHO and those recognized by research. Study tries to determine medical and biological variables like bleeding signs, disturbed LFT's, occurrence of protein and blood in the urine as probable forecasters of serious Dengue Fever. This can help in developing an aggressive strategy for dealing with such patients. Research revealed that 
extent of Dengue Fever as a risk for producing DSS can be forecasted by occurrence of excessive IgG levels, considerable P-value of 0.001; bleeding signs, p-value $<0.0001$; and elevated serum AST \& ALT, p-value of 0.01 \&0.004 accordingly. Although hazard for producing dengue hemorrhagic fever in patient with dengue fever can be forecasted through bleeding existence, URBC \& URP and elevated ALT in serum (Khan et al. 2013).

\section{Dengue hemorrhagic fever surveillance}

(Chairulfatah et al. 2001) In Indonesia, it is rule to inform about cases of dengue hemorrhagic fever (DHF) during $24 \mathrm{~h}$ to the local health authority. The objective of this study was to assess the competence, precision and communication delay of this information processes. In four main hospitals of the city of Bandung, medical archives of hospitalized DHF cases admitted between April 1994 and March 1995 were revised. This list of DHF cases was matched with the list of informed cases to the Bandung Municipality Health Office. Throughout the research duration, 569 dengue hemorrhagic cases and 81 dengue shock syndrome (DSS) cases were detected. Only 199 (31\%) of the 650 hospitalized cases with assumed DSS/DHF were informed to the Bandung Municipality Health Office. The proportion of fatal cases was considerably lower in all hospitalised cases i.e.1.7\% than among informed cases i.e. 2.5\%. In only 443 of the 583 hospitalised cases (76\%) in whom a dengue serological investigation was implemented, had this test positive. Of the 199 reported DHF/DSS cases151 (76\%) had a positive haemagglutination inhibition test. This study shows that the surveillance system for DHF/DSS in Bandung should be strengthened. DHF/DSS cases should be reported on the basis of a diagnosis made during hospitalisation preferably after a serological confirmation is obtained. (Chairulfatah et al. 2001)

\section{Outbreak in lahore}

(Humayoun et al. 2008) In a study conducted in Lahore in 2008 Out of the total of 110 dengue infected patients, 70 were male and 40 were female. The most common symptoms include fever (100\%), myalgia (68.2\%), headache (55.5\%), nausea (39.1\%), skin rash (53.6\%), mucocutaneous hemorrhagic manifestations (58.2\%), and ocular pain (20\%). Classic dengue fever (DF) was seen in $41.8 \%$ of the patients, $56.4 \%$ had dengue hemorrhagic fever (DHF), and only $1.8 \%$ developed dengue shock syndrome (DSS). Thrombocytopenia, leukopenia, and abnormal aspartate aminotransferase (AST)/alanine aminotransferase (ALT) were more frequently encountered in DHF and DSS as compared to DF. Ten patients had DEN4, five had DEN2, and two had DEN3 serotypes. The high frequency of DHF during the 2008 outbreak and the presence of three different dengue serotypes, emphasize the need to prevent and control dengue infection. Health authorities should consider strengthening surveillance for dengue infection, given the potential for future outbreaks with increased severity. It is also suggested that primary care physicians should be educated regarding recognition of DHF and to identify patients at high risk of developing DHF and DSS. (Humayoun et al.) In a study conducted in Lahore 2011about DHF outbreak found that there was 359 probable DF and 281 confirmed DF cases. The development of DHF, neurological manifestations and overall mortality was more frequent in confirmed DF group. Comparison between DHF/DSS and DF cases revealed a significant difference in vomiting ( $\mathrm{p}=0.04)$, purpuric rash $(p<0.001)$, systolic blood pressure $(p=0.002)$, serum ALT $(p<0.001)$, hospital stay ( $\mathrm{p}<0.001)$, neurological involvement $(\mathrm{p}<0.001)$ and coagulopathy $(\mathrm{p}<0.001)$ between the two groups. Among 159 DHF patients, 108 (67.9\%) had bleeding from gums and oral cavity, 73 (45.9\%) had haemetemesis and 82 (51.5\%) malaena, 41 (25.8\%) had epistaxis, 12 (7.5\%) developed intracranial bleeding, 18 (11\%) had hematuria, 12 (7.5\%) had fresh bleeding per rectum and 37 (23\%) developed haemoptysis. Overall mortality was 3\%, but mortality in DHF/DSS cases was $6 \%$ and $41.6 \%$ for DSS cases. Logistic regression analysis showed that abdominal pain, purpuric rash, ascites, thrombocytopenia, coagulopathy and raised ALT had a statistically significant predictability for developing DHF. (Ahmed et al.) 
Texila International Journal of Public Health

Volume 4, Issue 4, Dec 2016

\section{Diagnosis}

(Halstead, 2007) Diagnosis of dengue falls into two stages: stage I, fever and viraemia accompanied by NS1 antigens in blood; and stage II, the early post-febrile period lasting a few weeks when IgM and IgG antibodies are in excess. During primary infection, viraemia more or less coincides with fever (figure 3). However, during a secondary infection, the duration of viraemia can be 2 or 3 days, whereas presence of NS1 antigens in blood lasts somewhat longer. The diagnostic importance of the two stages of dengue infection should be understood by the doctor. An inexpensive, rapid, sensitive, and specific test is needed to diagnose dengue during the febrile stage. One such test is marketed by Bio-Rad and uses a dengue group-specific NS1 monoclonal antibody in an ELISA format to detect dengue NS1 antigen in blood. This test confirmed $85 \%$ of PCR-positive serum samples.

\section{Policy making for prevention}

(DeRoeck et al,. 2003) A survey of policymakers and other influential professionals in four Southeast Asian countries (Cambodia, Indonesia, Philippines and Vietnam) was conducted to determine policymakers' views on the public health importance of dengue fever and dengue hemorrhagic fever (DHF), the need for a vaccine and the determinants influencing its potential introduction. The survey, which involved face-to-face interviews with policymakers, health programme managers, researchers, opinion leaders and other key informants, revealed an almost uniformly high level of concern about dengue fever/DHF and a high perceived need for a dengue vaccine. Several characteristics of the disease contribute to this high sense of priority, including its geographic spread, occurrence in outbreaks, the recurrent risk of infection each dengue season, its severity and the difficulty in diagnosis and management, its urban predominance, its burden on hospitals, and its economic toll on governments and families. Research felt to be key to future decision-making regarding dengue vaccine introduction include: disease surveillance studies, in-country vaccine trials or pilot projects, and studies on the economic burden of dengue and the cost-effectiveness of dengue vaccines. The results suggest favorable conditions for public and private sector markets for dengue vaccines and the need for creative financing strategies to ensure their accessibility to poor children in dengue-endemic countries.(DeRoeck et al. 2003)

(Gonzalez et al. 2005) A dengue 3 epidemic occurred in Havana City from June 2001 to March 2002. 12,889 cases were reported, with 81 DHF cases. From this, 76serologically confirmed cases were studied descriptively. Results showed Bronchial asthma and white race were important risk factors for the severe form of the disease. Fever (100\%), headache (92.1\%), myalgia (76.3\%), arthralgia (73.7\%) and retro-orbital pain (57.7\%) were the most frequent general symptoms. Vomiting and abdominal pain were observed in $59.2 \%$ and $48.6 \%$ of cases, respectively. The most common bleeding site was the vagina (64\%), followed by the skin (55.2\%). Eighteen patients (23.6\%) had shock syndrome. Laboratory findings included thrombocytopenia (100\%), hemoconcentration (93.4\%), an increase in liver enzymes (82.8\%), and leukopenia (71\%). Ultrasound detected thickening of the gallbladder wall in $35.1 \%$, pleural effusion in $20.3 \%$, and splenomegaly in $12.9 \%$ of cases. These findings contribute to a better understanding of the clinical aspects of DHF in adult patients due to the dengue 3 virus. (Gonzalez et al. 2005). In Lahore during 2006 epidemic this report on the Lab based surveillance of a public hospital where most of the patients from Lahore city or its suburbs. This study confirmed the presence of epidemic of DHF in Pakistan and suggests that there are be more than one serotypes present in Lahore. Visitors to Pakistan should be warned about the possibility of dengue infection and encouraged to use mosquito repellents. Clinicians in Pakistan should consider dengue in their differential diagnosis of patients presenting with fever or hemorrhage of unknown cause. This could lead to improved clinical and virologic surveillance for dengue. (Shahzad et al. 2007)

(Gibbons et al,. 2002) In study about incidence in Lahore among the 341 acute cases, 166 (48.7\%) were confirmed by IgM dengue specific kit. IgG was used on 200 suspected reinfected patients. Among them 79 (39.5\%) were positive, 3 (1.5\%) in gray zone and 118 
(59\%) were negative. Male to female ratio was 1.25:1. Most patients presented typical sign and symptoms of fever, headache, myalgia, anorexia, malaise, and skin rash and retro orbital pain in 98, 81, 75, 63, 47 and 41\% respectively in descending order. Among 245 confirmed dengue fever patients 43 (17.6\%) were considered dengue hemorrhagic fever cases on the basis of lab and clinical findings. More prevalence has been observed in old age (37.8\%) as compared to children (7.1\%) in age group 1-15 years. Continuous surveillance and education of the clinician is essential for the recognition of the risk factors of dengue hemorrhagic fever for early diagnosis and management. (Mahmood et al. 2009)

\section{Risk factors for dengue hemorrhagic fever}

(Pang et al. 2012) A study explored demographic and co morbidity risk factors for DHF in adult dengue epidemics in Singapore in year 2006 (predominantly serotype 1) and in year 2007-2008 (predominantly serotype 2). Retrospective case-control study was conducted with 149 DHF and 326 dengue fever (DF Adult dengue patients in Singapore who were 30-49 years, Chinese, female, had diabetes or diabetes with hypertension were at greater risk of developing DHF during epidemic of predominantly serotype 2 . These risk factors can be used to guide triaging of patients who require closer clinical monitoring and early hospitalization in Singapore, when confirmed in more studies. (Pang et al.)

In an age- and sex-matched case control study, total of 132 cases of dengue hemorrhagic fever/dengue shock syndrome and 249 randomly selected controls were recruited from two major teaching hospitals of Lahore, Pakistan. A semi structured questionnaire was used to collect data through interview and by reviewing clinical records. Odds of developing dengue hemorrhagic fever (DHF) and dengue shock syndrome (DSS) among diabetics are higher than in controls, but this association was not found statistically significant (OR. 1.26; 95\% CI. 0.78-2.03; $P=0.34)$. Similarly, no association was observed in individuals suffering from hypertension (OR. 0.93; 95\% CI. 0.57-1.49; $P=0.76$ ). Odds of developing DHF and DSS were higher for bronchial asthma (adjusted OR. 1.34) and pulmonary tuberculosis (adjusted OR. 1.41); however $P$ values were insignificant. Presence of diabetes mellitus, hypertension, ischemic heart disease and bronchial asthma among patients contracted dengue fever will not increase the risk of dengue hemorrhagic fever and dengue shock syndrome. (Mahmood et al. 2013) Although the liver is not a major target organ, pathologic findings including centrilobular necrosis, fatty change, Kupffer cell hyperplasia, acidophilic bodies, and monocyte infiltration of the portal tracts have been reported in patients with and/or dengue shocksyndrome (DSS) (Bhamarapravati et al, 1967; Burke, 1968). With such involvement, it would be expected that liver function tests would be abnormal. Liver involvement in dengue infection has been reported to be mild and manifest by raised liver enzymes. Of late there have been reports of fulminant hepatitis with high mortality in-patients with dengue infection (George, 1987; Suvatte et al, 1990). Innis et al (1990) reviewed the clinical course and liver histopathology of 19 fatal cases of dengue infection. In this study acute liver failure had been identified as a cause of death in DHF by dengue virus types 1 to 3 . The mode of liver injury whether a direct effect of the virus replication or a consequence of host response to infection could not be inferred.(Wahid et al. 2000)

Most DHF cases occur after sequential heterotypic DV infections (secondary infection), and circulating DV levels early in illness correlate with increasing dengue disease severity. The DV nonstructural protein NS1 is a $46-50-\mathrm{kDa}$ glycoprotein expressed in infected mammalian cells in both membrane-associated (mNS1) and secreted (sNS1) forms and is not a component of the dengue virion. Circulating sNS1 has been detected in acute-phase serum samples of patients with DV infections. The goals of this study were to determine whether plasma levels of sNS1 correlate with viremialevels, whether they are higher in DHF than in DF, and whether sNS1 levels early in illness could identify patients at risk of developing DHF. Immune complex formation with sNS1 and sNS1 binding to endothelial cells have been proposed as potential factors in DHF pathogenesis. Whether high circulating levels of 
Texila International Journal of Public Health

Volume 4, Issue 4, Dec 2016

antibody-bound or free sNS1 protein following peak viremia play a direct role in the pathogenesis of DHF is unknown and will require further investigation (Libraty et al. 2002).

\section{Treatment}

(Gibbons et al,. 2002) No specific therapeutic agents exist for dengue; steroids, antivirals, orcarbazochrome (which decreases capillary permeability) have no proven role. In patients without shock, oral hydration should be started early. Paracetamol (aspirin and other non-steroidalanti- inflammatory drugs should be avoided owing to the increased risk for Reye's syndrome and haemorrhage) can be used for fever and analgesia. Assessment of the patient's condition includes packed cell volume, platelet count, liver function tests, prothrombin time, partial thromboplastin time, electrolytes, and blood gas analysis. The patient's clinical condition should be monitored until at least 24 hours after defervesence because of the risk of shock

\section{Statement of problem}

- To identify the potential risk factors for Dengue Hemorrhagic Fever.

- Descriptive epidemiology of deaths with Dengue Hemorrhagic Fever.

- Spatial distribution of Dengue Hemorrhagic Fever in catchment areas of Shalamar.

\section{Materials and methods}

\subsection{Study design:}

A retrospective study of DHF was conducted in ICU and medical units of tertiary care hospital Lahore city from April 2016 to October 2016 to collect data from 2009 to 2016 about cases of DHF.

\section{Study area}

This study was conducted at Intensive care Unit (ICU) in one of the tertiary care hospitals of Lahore city. This tertiary care hospital contains 350 beds and lies between $30^{\circ} 34^{\prime}-30^{\circ} 31^{\prime}$ $\mathrm{N}$ and $74^{\circ} 22^{\prime}-74^{\circ} 47 \mathrm{E}$. The study area (ICU) is located in the hospital adjacent to ObsGynae ward (Labour room and Gynea operation theatre) and General operation theatre (GOT). Comprises of 9 beds; 3 beds (Bed-1 to Bed-3) allocated for patients with surgical or gynecological problems and 6 beds (Bed-4 to Bed-9) allocated for patients with medical problems. This intensive care unit was only admitting the patients requiring close monitoring or aggressive interventions referred from other wards or emergency room of the hospital. It was estimated that on average each 1 patient was referred to be admitted in ICU from other wards or emergency room. Control data was collected from different medical units of hospital.

\section{Sample size}

All cases of DHF deaths from 2009 to 2013 were included in the study, who were admitted in ICU after referral from different units with the diagnosis of DHF. A case was matched with a control on the ratio of 1:1. Controls were selected from confirmed cases of DF who survived.

\section{Selection of case}

A case was selected as case if he/she was confirmed dead by the hospital authorities and whose death was notified to health authorities due to DHF.

\section{Selection of controls}

A control was selected randomly from patients confirmed for DF who was cured and survived. 


\section{Inclusion criteria}

ELISA (Enzyme linked immuno-absorbent assay) confirmed Dengue fever patients admitted to Shalamar Hospital Lahore and willing to participate were included.

\section{Exclusion criteria}

Patients who were not confirmed by ELISA, complicated cases, or some other diseases with clinical signs similar to DF and those who refuse to participate were excluded from the study.

\section{Data collection procedure}

Data about cases was collected from the hospital records and close family member of the dead patient and from control on a structured questionnaire developed by the investigator. Questionnaires was completed in a face-to face interview \& telephonic interview with the family member of cases (dead patients) and controls (treated patients) and data about age, gender, demographic information, diabetes status, Hypertension, Asthma, allergies treated with corticosteroids, smoking, TB, paralysis and other relevant factors was collected. Purpose of the study was explained to all the attendants/relatives of the patients and verbal consent was taken prior to investigation.

\section{Statistical design}

To manage the data, a database was created in Microsoft Office excel 2010. The data analysis was done using SPSS v.16 software. Univariable analysis was conducted to find out the association between potential risk factors and the occurrence of deaths. Chi-square test was used to determine the relationship between gender, age group, Diabetes, Hypertension, TB Asthma, Allergies, Smoking, and Paralysis and outcome of interest (death among DHF patients). Factors found significant $(\mathrm{p}<0.25)$ were included in the Multivariable analysis. A pvalue less than 0.05 , was considered statistically significant in multivariable analysis (Hosmer et al. 2004).

\section{Results}

A total of 53 patients admitted to Intensive Care Unit from 2009-2013 were followed during the study period. These patients/ attendants were asked about the presence of comorbidities like Diabetes, Hypertension, Asthma, Allergies and occurrence of bleeding phenomena was recorded in the structured questionnaire attached (Annexure I). After the collection of data, each patient was matched with the inclusion and exclusion criteria. On matching 46 patients out of 53 met the inclusion criteria and included in the study and rest of the 7 patients were excluded from the study. And 46 controls were selected from medical units with the diagnosis of Dengue fever.

Table 4.1 Number of total patients included in study meeting inclusion criteria

\begin{tabular}{|l|l|l|}
\hline Status & Number & Percentage \\
\hline $\begin{array}{l}\text { Patients who met the } \\
\text { inclusion criteria }\end{array}$ & 46 & $86 \%$ \\
\hline $\begin{array}{l}\text { Patients who did not meet the } \\
\text { inclusion criteria }\end{array}$ & 7 & $14 \%$ \\
\hline $\begin{array}{l}\text { Total Number of Patients } \\
\text { followed }\end{array}$ & 53 & $100 \%$ \\
\hline
\end{tabular}


Texila International Journal of Public Health

Volume 4, Issue 4, Dec 2016

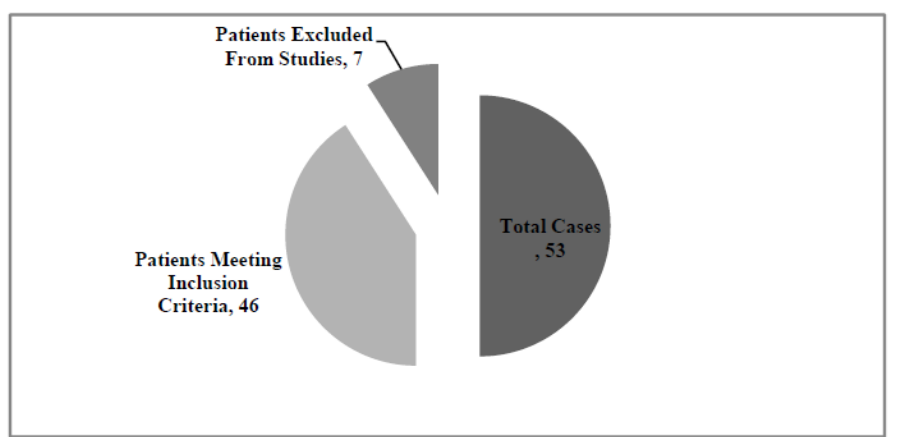

Fig. 4.1 Number of total patients included in study meeting inclusion criteria

Out of 53 patients who were selected during the study period $86 \%$ met the inclusion criteria i.e. they were confirmed cases of DHF. Rest of the $14 \%$ were excluded as they had very complicated condition or refused to participate in study.

Following table and figure shows the frequency distribution and bar charts of the patient's ages admitted to ICU and medical units with dengue and DHF. As it is visible in Table 4.2 that more patients are in younger age group.

Table 4.2 Age distribution according to groups

\begin{tabular}{|l|l|l|l|l|}
\hline \multicolumn{1}{|c|}{ Age } & Frequency & Percent & $\begin{array}{c}\text { Valid } \\
\text { Percent }\end{array}$ & $\begin{array}{c}\text { Cumulative } \\
\text { Percent }\end{array}$ \\
\hline $0-20$ & 7 & 7.6 & 7.6 & 7.6 \\
\hline $21-40$ & 40 & 43.5 & 43.5 & 51.1 \\
\hline $41-60$ & 31 & 33.7 & 33.7 & 84.8 \\
\hline $61-80$ & 11 & 12.0 & 12.0 & 96.7 \\
\hline $81-100$ & 3 & 3.3 & 3.3 & 100.0 \\
\hline Total & 92 & 100.0 & 100.0 & \\
\hline
\end{tabular}

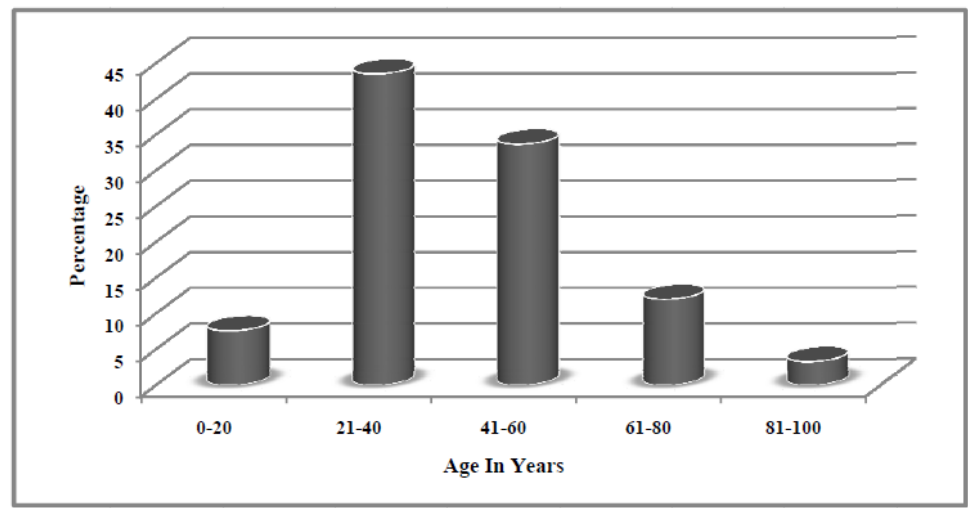

Figure 4.2 Frequency Distribution of cases and controls according to age groups

Figure. 4.3, represents the frequncy distribution of cases and controls according to gender. It shows that percentage of male patients is higher as compared to females. 


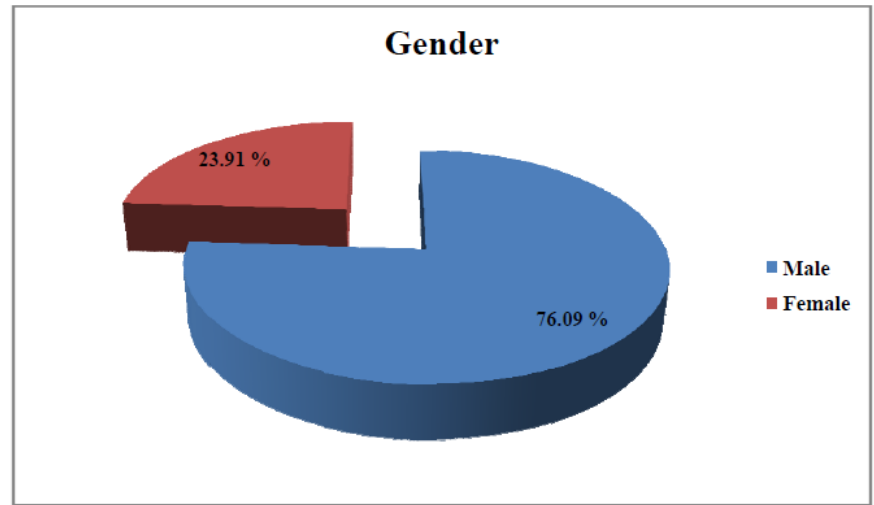

Figure 4.3. Gender based distribution of all patients

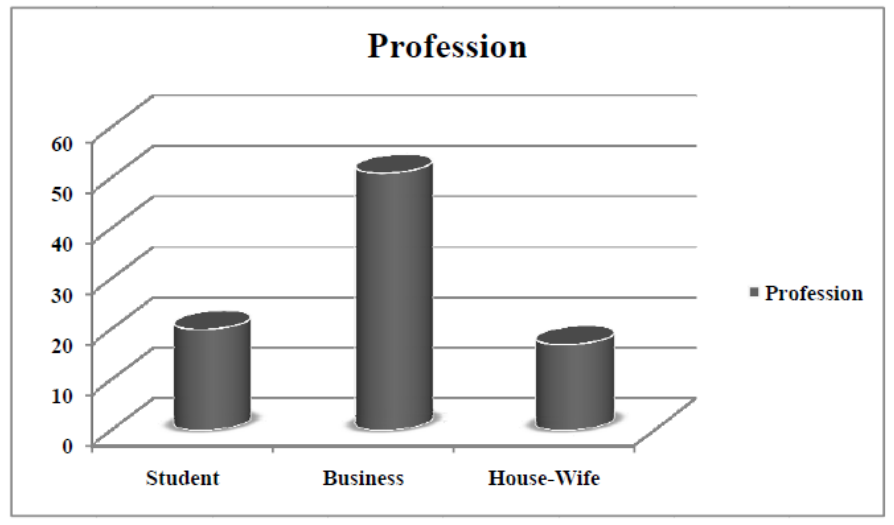

Figure 4.4. Profession wise distribution of all patients

Figure 4.4 shows the body temperature distribution of the cases and controls and it is shown that more patients are in the temperature range of 100-102 F.

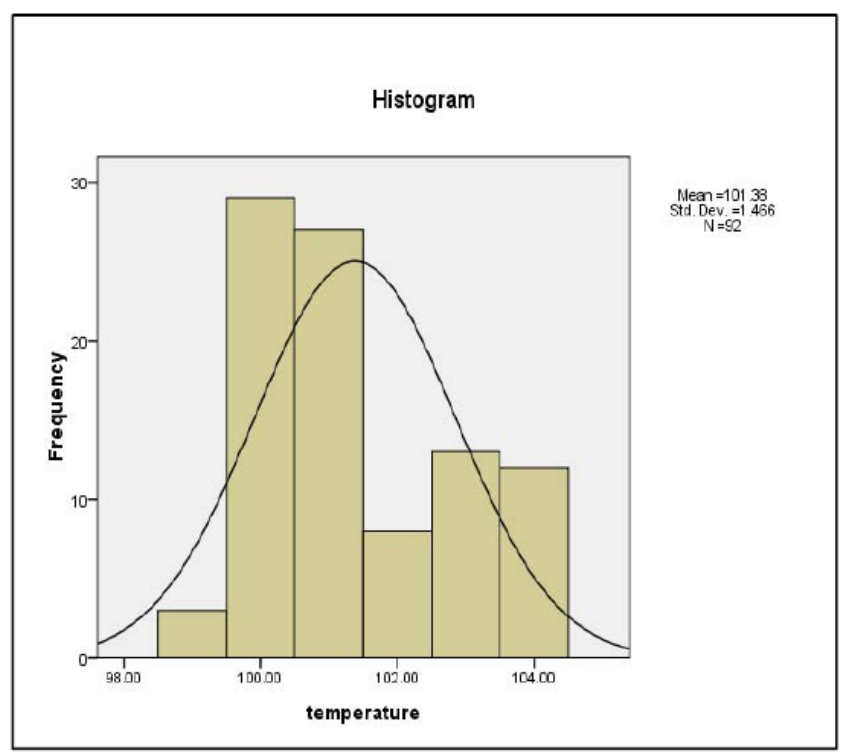

Figure 4.5 Body Temperature (in Fahrenheit) frequency chart

Table 4.3 shows the chi square association of diabetes mellitus among cases and controls. P-value $<0.01$ is considered highly significant for this association. 
Texila International Journal of Public Health

Volume 4, Issue 4, Dec 2016

Table 4.3 Chi square test of diabetes and outcome of interest

\begin{tabular}{|l|l|l|l|l|l|}
\hline & Value & Df & $\begin{array}{l}\text { Asymp. Sig. } \\
\text { (2-sided) }\end{array}$ & $\begin{array}{l}\text { Exact Sig. } \\
\text { (2-sided) }\end{array}$ & $\begin{array}{l}\text { Exact Sig. } \\
\text { (1-sided) }\end{array}$ \\
\hline Pearson Chi-Square & $21.204^{\mathrm{a}}$ & 1 & .001 & & \\
Continuity Correction $^{\mathrm{b}}$ & 19.320 & 1 & .000 & & \\
Likelihood Ratio & 22.138 & 1 & .000 & .000 & .000 \\
Fisher's Exact Test & & & & & \\
$\mathbf{N}$ of Valid Cases & 92 & & & & \\
\hline
\end{tabular}

a. 0 cells $(.0 \%)$ have expected count less than 5 . The minimum expected count is 21.00 .

b. Computed only for a $2 \times 2$ table

Number of patients having diabetes mellitus varied from group to group as illustrated in following figure.

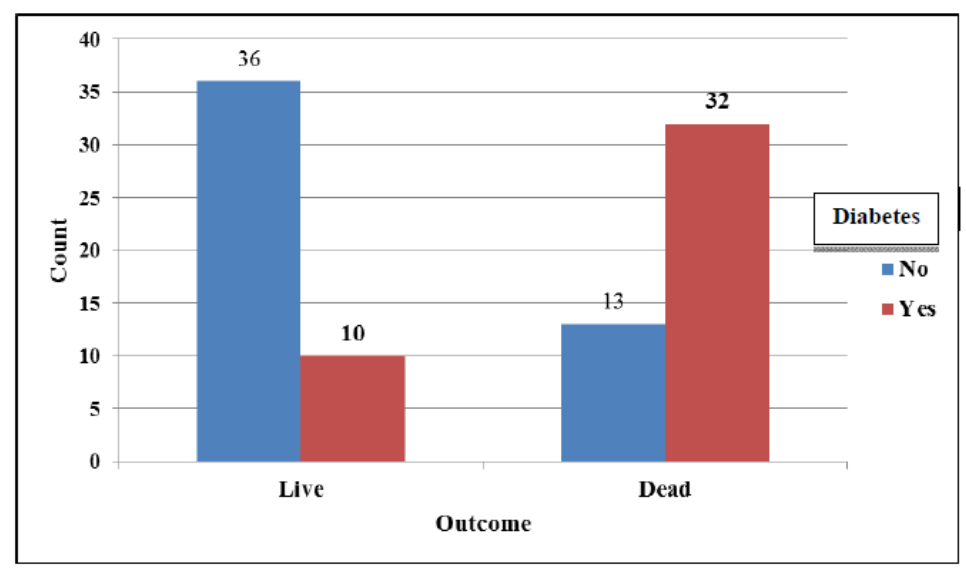

Fig 4.6 Distribution of Diabetes Melitus in different groups

Table 4.4 shows the chi square association of Hypertension among cases and controls. $\mathrm{P}$-value $<0.02$ is considered highly significant for this association.

Table 4.4 chi square test of Hypertension with outcome of interest

\begin{tabular}{|l|l|l|l|l|l|}
\hline & Value & Df & $\begin{array}{l}\text { Asymp. Sig. } \\
\text { (2-sided) }\end{array}$ & $\begin{array}{l}\text { Exact Sig. } \\
\text { (2-sided) }\end{array}$ & $\begin{array}{l}\text { Exact Sig. } \\
\text { (1-sided) }\end{array}$ \\
\hline $\begin{array}{l}\text { Pearson Chi-Square } \\
\text { Continuity Correction }\end{array}$ & $9.787^{\mathrm{a}}$ & 1 & .002 & & \\
Likelihood Ratio & 8.526 & 1 & .004 & & \\
$\begin{array}{l}\text { Fisher's Exact Test } \\
\text { N of Valid Cases }\end{array}$ & 9.969 & 1 & .002 & .003 & .002 \\
\hline
\end{tabular}

a. 0 cells $(.0 \%)$ have expected count less than 5 . The minimum expected count is 22.50 .

b. Computed only for a $2 \times 2$ table 
Number of patients having hypertension varied from group to group as illustrated in following figure.

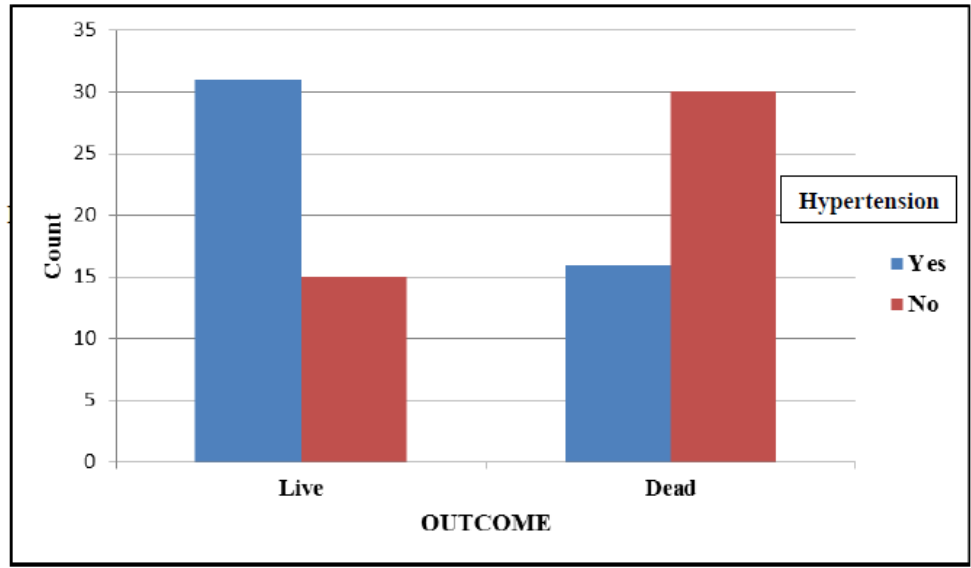

Fig 4.7 Frequency distribution of Hypertension

Table 4.5 cross tabulation of age groups according to cases and controls

\begin{tabular}{|c|c|c|c|c|c|c|c|c|}
\hline & \multicolumn{5}{|c|}{ Age in years } & \multirow{2}{*}{ Total } \\
\hline & & & $0-20$ & $21-40$ & $41-60$ & $61-80$ & |81-100 - & \\
\hline \multirow{4}{*}{ 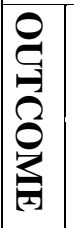 } & 胥: & Count & 3 & 24 & 14 & 4 & 1 & 46 \\
\hline & D & \% within OUTCOME & $6.5 \%$ & $52.2 \%$ & $30.4 \%$ & $8.7 \%$ & $2.2 \%$ & $100.0 \%$ \\
\hline & $\underset{D}{\nabla}$ & Count & 4 & 16 & 17 & 7 & 2 & 46 \\
\hline & $\approx$ & $\%$ within OUTCOME & $8.7 \%$ & $34.8 \%$ & $37.0 \%$ & $15.2 \%$ & $4.3 \%$ & $100.0 \%$ \\
\hline \multirow{2}{*}{\multicolumn{2}{|c|}{ Total }} & Count & & & & & 3 & \\
\hline & & $\%$ within OUTCOME & $7.6 \%$ & $43.5 \%$ & $33.7 \%$ & $12.0 \%$ & $3.3 \%$ & $100.0 \%$ \\
\hline
\end{tabular}

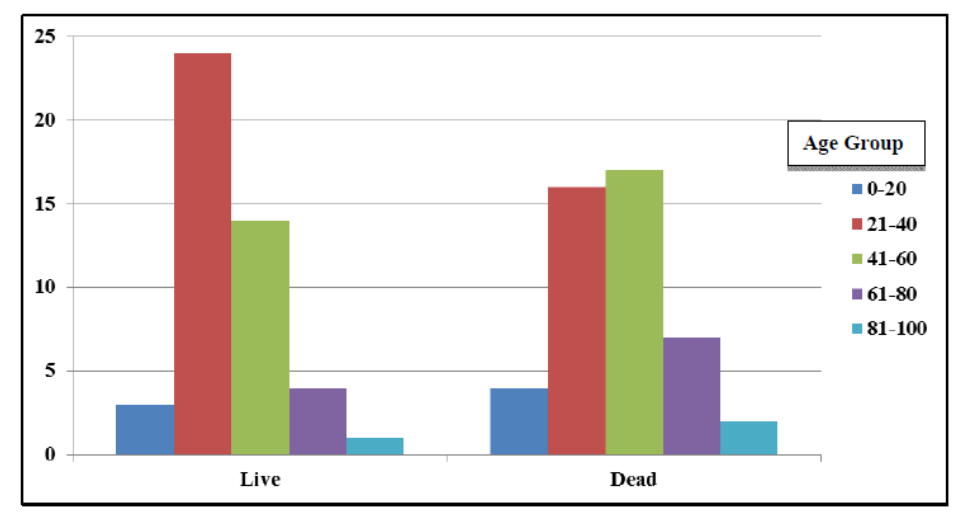

Fig 4.8 Distribution of age among cases and control 
Texila International Journal of Public Health

Volume 4, Issue 4, Dec 2016

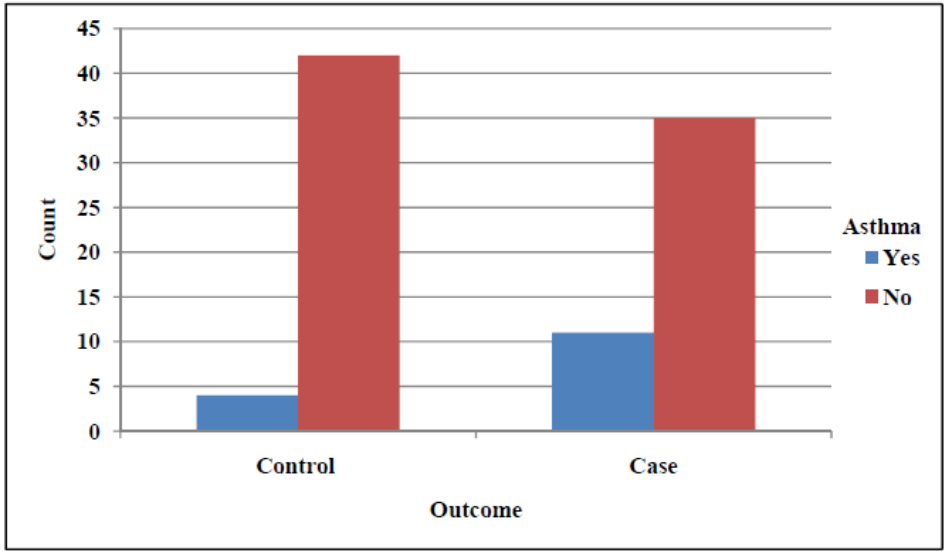

Fig 4.9 Frequency Distribution of Asthma among cases and control

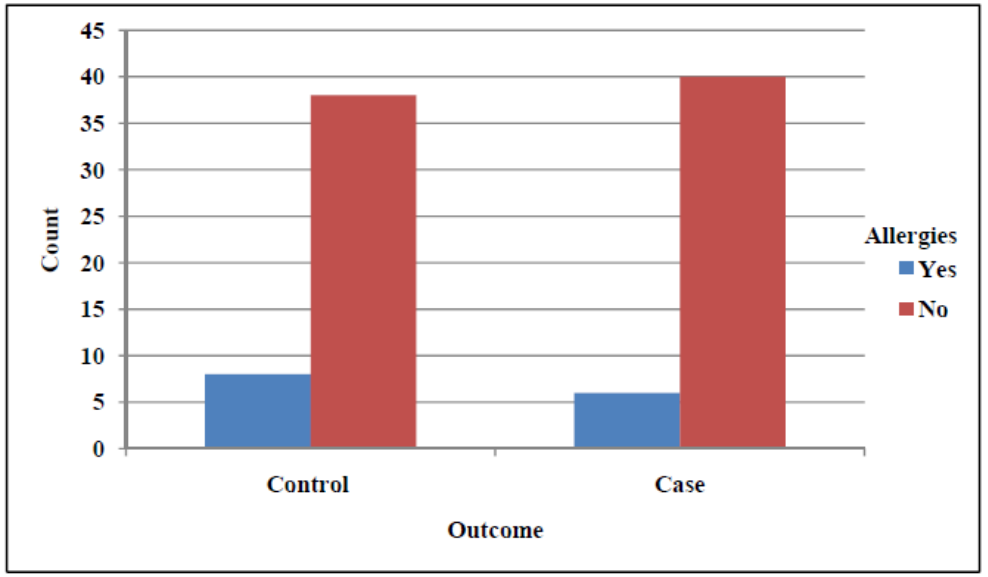

Fig 4.10 Frequency Distribution of Allergies among cases and control

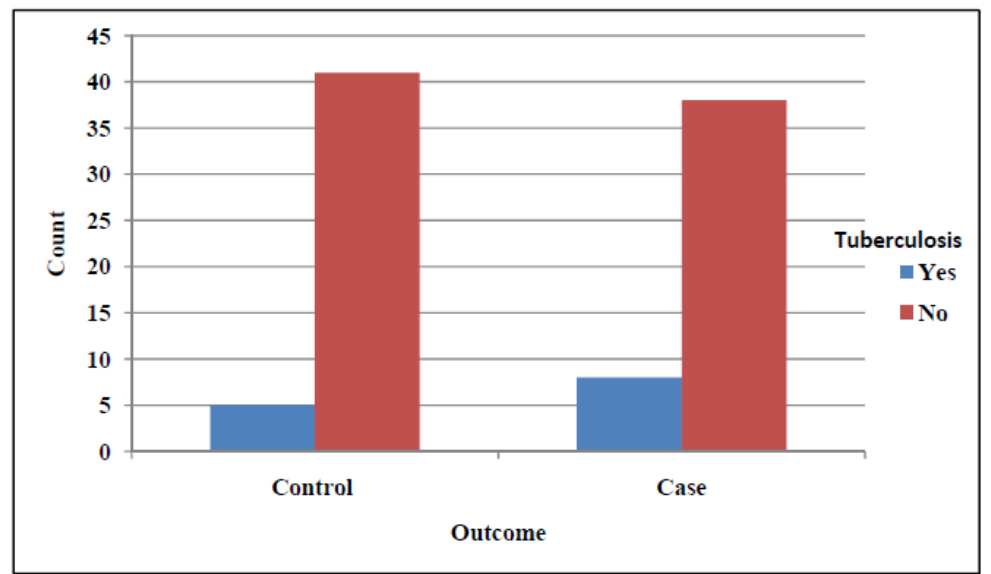

Fig 4.11 Frequency Distribution of Tuberculosis among cases and control 
Texila International Journal of Public Health

Volume 4, Issue 4, Dec 2016

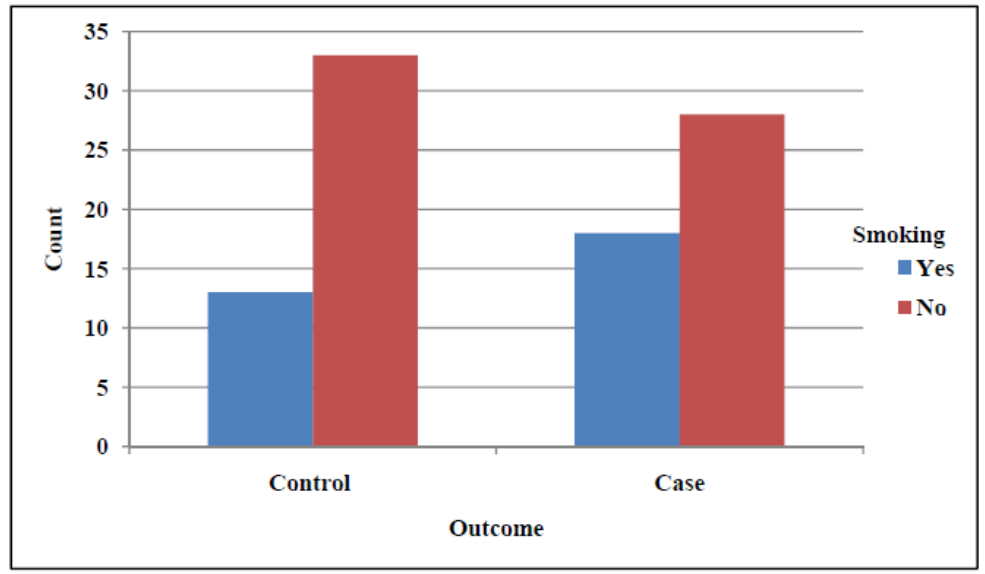

Fig 4.12 Frequency Distribution of Smoking among cases and control

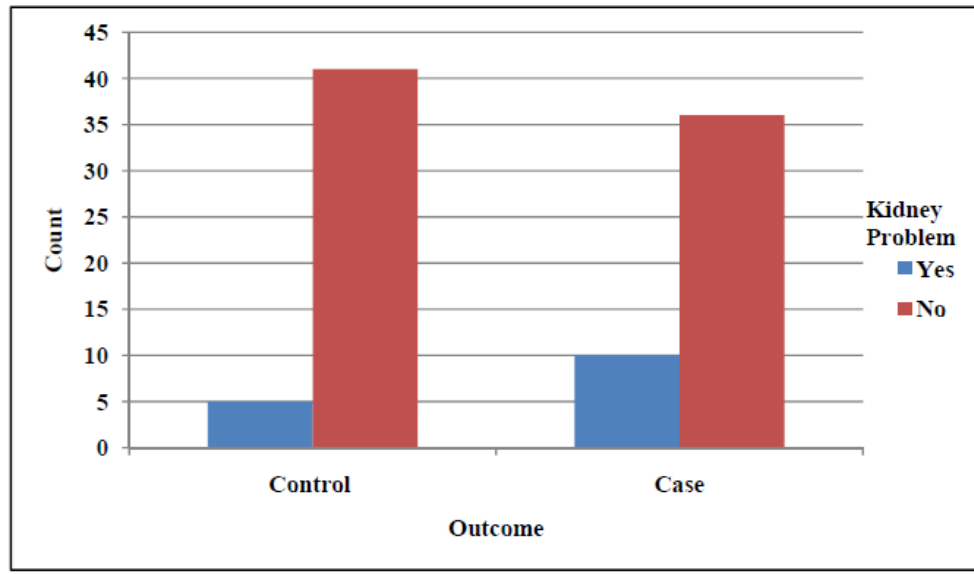

Fig 4.13 Frequency Distribution of Kidney Problems among cases and control

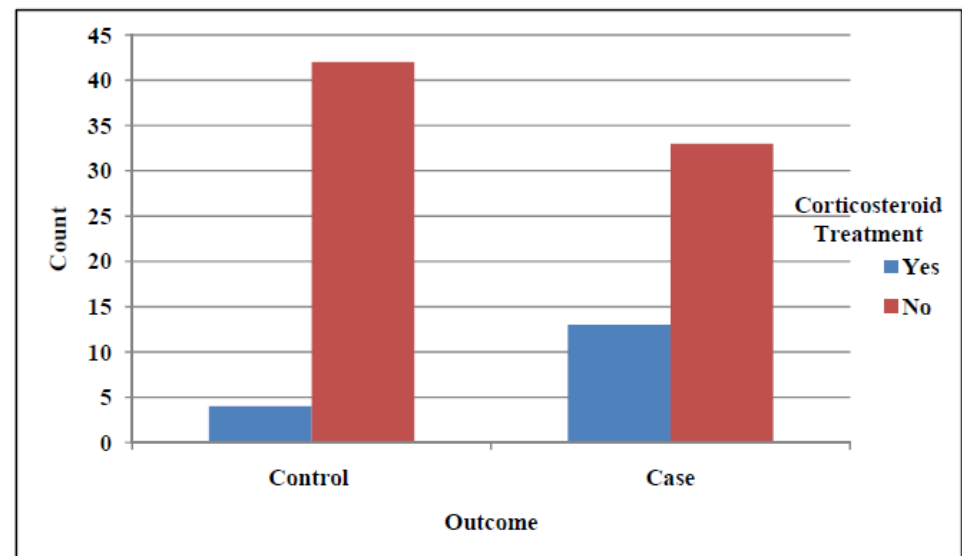

Fig 4.14 Frequency Distribution of Corticosteroid Treatment among cases and control 
Texila International Journal of Public Health

Volume 4, Issue 4, Dec 2016

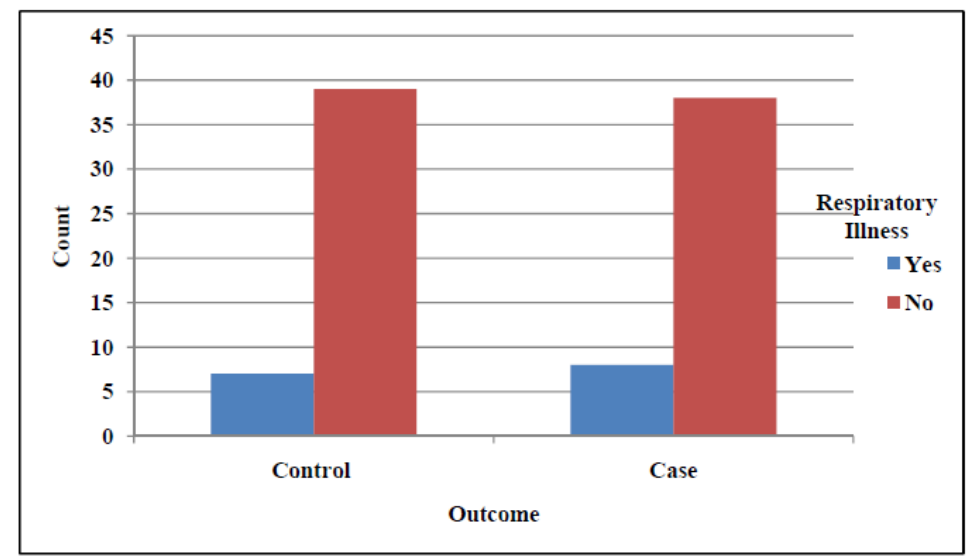

Fig 4.15 Frequency Distribution of Respiratory Illness among cases and control

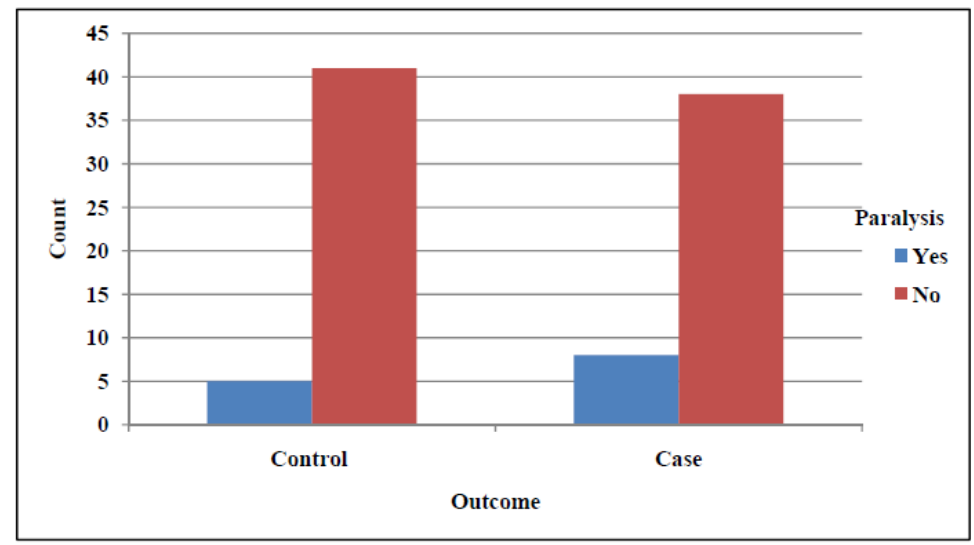

Fig 4.16 Frequency Distribution of Paralysis among cases and control

\section{Univariable analysis}

Table 4.6 Results of univariable analysis of the possible risk factors and indicators of DHF. Linear regression model was used to study the associations between the risk factors variables and DHF.

\begin{tabular}{|c|c|c|c|c|c|c|}
\hline Variable & $\begin{array}{l}\text { Level of } \\
\text { response }\end{array}$ & Case & Control & OR Ratio & $95 \%$ CI & P-value \\
\hline \multirow[t]{2}{*}{ Gender } & Female & 8 & 13 & \multirow{2}{*}{2.2} & \multirow{2}{*}{$\begin{array}{l}0.7644- \\
6.332 \\
\end{array}$} & \multirow{2}{*}{0.144} \\
\hline & Male & 38 & 32 & & & \\
\hline \multirow[t]{2}{*}{ Diabetes } & Yes & 32 & 10 & \multirow{2}{*}{4.667} & \multirow{2}{*}{$1.932-11.27$} & \multirow{2}{*}{0.000617} \\
\hline & No & 14 & 36 & & & \\
\hline \multirow{2}{*}{ Hypertension } & Yes & 31 & 14 & \multirow{2}{*}{9.5} & \multirow{2}{*}{$2.213-40.78$} & \multirow{2}{*}{0.00246} \\
\hline & No & 15 & 32 & & & \\
\hline \multirow[t]{2}{*}{ Asthma } & Yes & 11 & 4 & \multirow{2}{*}{2.75} & \multirow{2}{*}{$\begin{array}{l}0.8757- \\
8.636\end{array}$} & \multirow{2}{*}{0.0832} \\
\hline & No & 35 & 42 & & & \\
\hline \multirow[t]{2}{*}{ Allergies } & Yes & 6 & 8 & \multirow{2}{*}{0.75} & \multirow{2}{*}{$\begin{array}{l}0.2602- \\
2.162\end{array}$} & \multirow{2}{*}{0.594} \\
\hline & No & 40 & 38 & & & \\
\hline \multirow[t]{2}{*}{ Tuberculosis } & Yes & 8 & 5 & \multirow{2}{*}{1.6} & \multirow{2}{*}{$\begin{array}{l}0.5234- \\
4.891\end{array}$} & \multirow{2}{*}{0.14} \\
\hline & No & 38 & 41 & & & \\
\hline \multirow[t]{2}{*}{ Smoking } & Yes & 18 & 13 & \multirow{2}{*}{1.5} & \multirow{2}{*}{$\begin{array}{l}0.6739- \\
3.339\end{array}$} & \multirow{2}{*}{0.321} \\
\hline & No & 28 & 33 & & & \\
\hline \multirow{2}{*}{$\begin{array}{l}\text { Kidney } \\
\text { Problem }\end{array}$} & Yes & 10 & 5 & \multirow{2}{*}{2.25} & \multirow{2}{*}{$\begin{array}{l}0.6929- \\
7.306\end{array}$} & \multirow{2}{*}{0.177} \\
\hline & No & 36 & 41 & & & \\
\hline
\end{tabular}




\begin{tabular}{|c|c|c|c|c|c|c|}
\hline \multirow{2}{*}{$\begin{array}{l}\text { Corticosteroid } \\
\text { Treatment }\end{array}$} & Yes & 13 & 4 & \multirow{2}{*}{3.25} & \multirow{2}{*}{$1.09-9.967$} & \multirow{2}{*}{0.0393} \\
\hline & No & 33 & 42 & & & \\
\hline \multirow{2}{*}{$\begin{array}{l}\text { Allergies } \\
\text { Treatment }\end{array}$} & Yes & 10 & 2 & \multirow{2}{*}{5} & \multirow{2}{*}{$1.096-22.82$} & \multirow{2}{*}{0.0377} \\
\hline & No & 36 & 44 & & & \\
\hline \multirow{2}{*}{$\begin{array}{l}\text { Respiratory } \\
\text { Illness }\end{array}$} & Yes & 8 & 7 & \multirow{2}{*}{1.167} & 0.3921- & \multirow{2}{*}{0.782} \\
\hline & No & 38 & 39 & & 3.471 & \\
\hline \multirow[t]{2}{*}{ Paralysis } & Yes & 8 & 5 & \multirow{2}{*}{1.6} & $0.5234-$ & \multirow{2}{*}{0.41} \\
\hline & No & 38 & 41 & & 4.891 & \\
\hline
\end{tabular}

Multivariable Analysis

Table 4.7 the results of multivariable analysis of the possible risk factors and indicators of DHF.

\begin{tabular}{|c|c|c|c|c|c|c|}
\hline Variable & $\begin{array}{l}\text { Level of } \\
\text { response }\end{array}$ & Case & Control & OR Ratio & $95 \%$ CI & P-value \\
\hline \multirow[t]{2}{*}{ Diabetes } & Yes & 32 & 10 & \multirow[t]{2}{*}{3.924} & \multirow[t]{2}{*}{$1.326-11.61$} & \multirow[t]{2}{*}{0.0135} \\
\hline & No & 14 & 36 & & & \\
\hline \multirow[t]{2}{*}{ Hypertension } & Yes & 31 & 14 & \multirow[t]{2}{*}{5.902} & \multirow[t]{2}{*}{$1.183-29.44$} & \multirow[t]{2}{*}{0.0304} \\
\hline & No & 15 & 32 & & & \\
\hline \multirow{2}{*}{$\begin{array}{l}\text { Corticosteroid } \\
\text { Treatment }\end{array}$} & Yes & 13 & 4 & \multirow[t]{2}{*}{5.647} & \multirow[t]{2}{*}{$1.298-24.57$} & \multirow[t]{2}{*}{0.0210} \\
\hline & No & 33 & 42 & & & \\
\hline
\end{tabular}

Fig 4.16 Spatial Distribution of cases and control

\section{Discussion}

Dengue is a major neglected tropical disease in the tropical and subtropical regions of the world. It is predominantly found in urban and semi-urban areas, and results in a wide spectrum of clinical manifestations, from asymptomatic infection, undifferentiated fever, dengue fever (DF) to severe infection known as dengue hemorrhagic fever (DHF) and dengue shock syndrome (DSS). It is estimated about 50 million infections occur annually, with 500,000 DHF cases and 22,000 deaths.(Pang et al. 2012)

Increases in human population, uncontrolled urbanization, and international travel can explain much of the spread and persistence of dengue in the twentieth and early twentyfirst centuries. It has been estimated that the minimum population size required to sustain dengue transmission is $10,000-1,000,000$. An estimated 3.5 billion people, or half the world's population, are at risk for DENV infection in tropical and subtropical countries (Jennifer et al. 2008).

This present study (cross sectional) conducted in intensive care unit (ICU) and Medical units at Shalamar Hospital Lahore, for a period of 4 months (January 2014 to April 2014). All patients admitting to ICU with diagnosis of DHF were taken as sample size for cases as it was only 9 bedded unit. This ICU in Shalamar is only for patients referred from other wards of the hospital and according to an estimate 1 patient admits to ICU/per day. Total 53 patients admitting in ICU were followed out of which 46 patients met the inclusion criteria and 7 patients were excluded from the study as they had very complicated condition. 


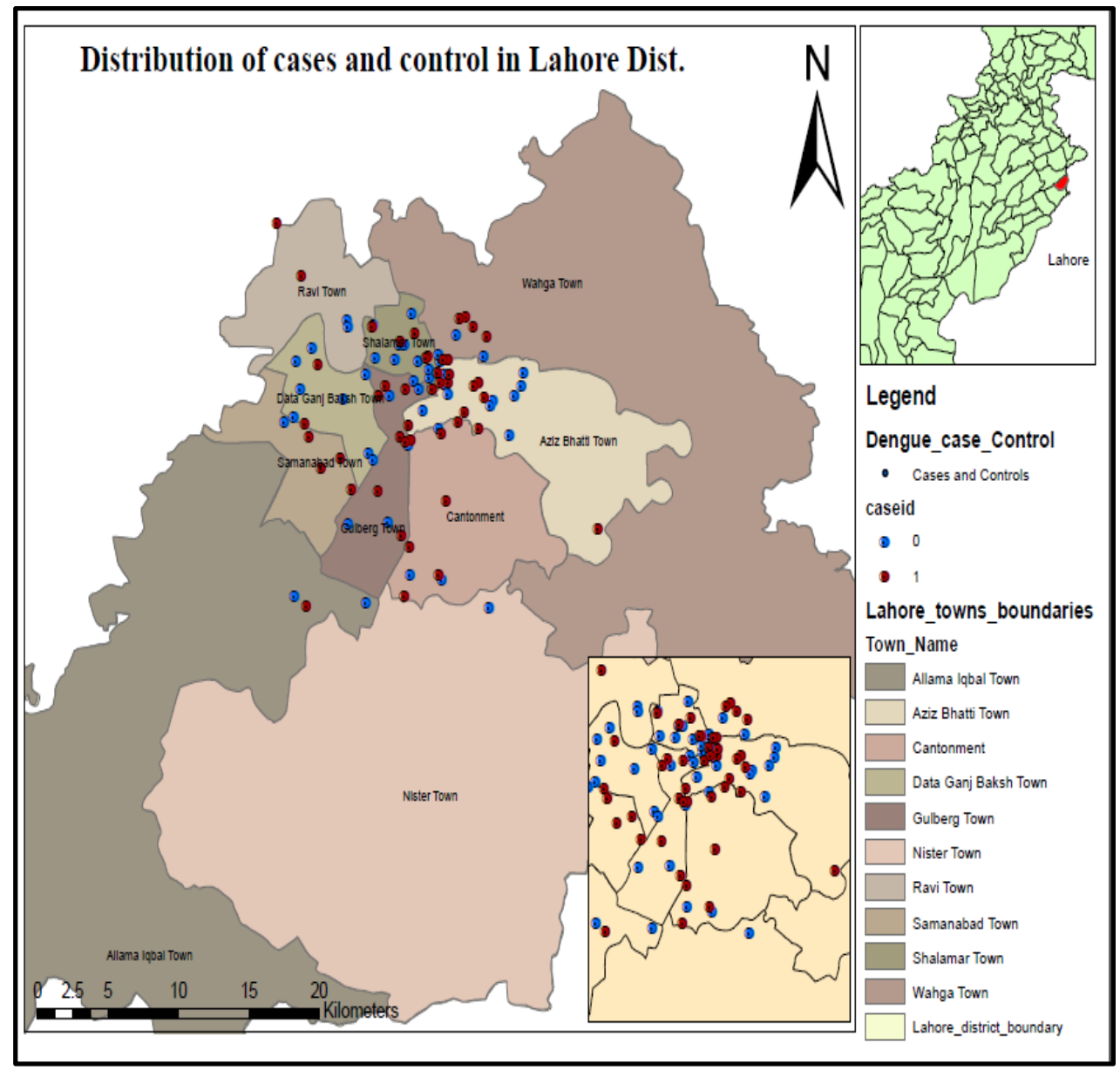

\section{Climate}

The term climate change refers to multiyear, large-scale changes in climate patterns, including fluctuations in both rainfall and temperature; global warming refers to an increase in the average global temperature related to the greenhouse effect. Lahore, the second biggest city of Pakistan lies between $31^{\circ} 15^{\prime}-31^{\circ} 45^{\prime} \mathrm{N}$ and $74^{\circ} 01^{\prime}-74^{\circ} 39^{\prime} \mathrm{E}$, covers a total land area of $1772 \mathrm{~km}^{2}$. The Climate of Lahore is a hot semi-arid and enjoy four weathers, during summer months of May to July, temperature climbs to $48^{\circ} \mathrm{C}$, follow by monsoon with heavy rainfall and winter months of December in which temperature drops to $0^{\circ} \mathrm{C}$. A $2{ }^{\circ} \mathrm{C}$ increase in temperature would simultaneously lengthen the lifespan of the mosquito and shorten the extrinsic incubation period of DENV, resulting in more infected mosquitoes for a longer period of time. (Fernandez et al. 2004) In this sense the climate of Lahore and surroundings is ideal for growth and propagation of dengue fever.

\section{Gender}

In this questionnaire based case control study, the proportion of male and female, was $76.09 \%$ and $23.91 \%$ respectively. Which clearly indicated that male patients were majorly victimized by dengue, outdoor activities of male gender may be a reason for it.

\section{Profession}

Amongst the 92 respondents, 20(21.4\%) belonged to group of students, 51 (55.4\%) patients were in business group of occupation and 17 (18.47\%) belonged to house wife group. These figures indicate that life style has no significant effect on occurrence of dengue. Precautionary measures are mandatory for everyone. 


\section{Age}

One of the important factors which may affect the occurrence of DHF is age. Results of this study indicate that $40 \%$ of cases were less than 30 years age. Most epidemiologic studies also find that children and adolescents under age 20 are at increased risk for DHF/DSS, independent of other risk factors, which may be related to increased capillary fragility and decreased tolerance for insult to microvascular integrity in this age group. (Jennifer et al. 2008).

DHF/DSS is characterized by rapid onset of capillary leakage accompanied by thrombocytopenia, altered homeostasis, and damage to the liver indicated by increases in aspartate aminotransferase and alanine aminotransferase (Halstead, 2007).

Results shown that bleeding signs and symptoms like Hematemesis, blood in stool, bleeding gums and positive urinalysis to be significantly associated with DSH cases where as petechiae and purpura (OR $0.06 \& 0.10$ respectively) are shown to be non-significant. Like previous research revealed that extent of Dengue Fever as a risk for producing DHF can be forecasted by occurrence of bleeding signs, p-value $<0.0001$; and elevated serum AST \& ALT, p-value of $0.01 \& 0.004$ accordingly.(Khan et al. 2004)

Since pathophysiology of this disease still poorly understood and there is no exact mechanism to predict or identify which would develop DHF and DSS there for evidence can be collected by screening patients at early stage for monitoring and intervention. This study was started on this hypothesis that certain comorbidities might increase the risk of developing DHF. Patients of DHF were compared with those who had only dengue fever for presence of comorbidities. In univariable analysis (Table 4.6) results of this study shown that risk factors like Diabetes (p-value0.000617) and OR 4.667, Hypertension (p-value 0.00246) OR 9.5, Asthma (p-value 0.0832) OR 2.75 and previous treatment for allergies (p-value 0.0377 ) to be significantly associated with the development of DHF whereas age, gender, smoking to be non-significant. And these results are consistent to a case control study which was done to test the hypothesis that the subjects suffering from diabetes mellitus, cardiovascular diseases, bronchial asthma, tuberculosis, and chronic liver disease have higher odds of developing dengue hemorrhagic fever and dengue shock syndrome if they contract dengue virus infection. Age difference was not found to be statistically significant.(Mahmood et al. 2013)

In multivariable analysis (Table 4.7) Diabetes (95\% CI- 1.326-11.61) with OR 3.924, Hypertension (95\% CI 1.183-29.44) with OR 5.902, Corticosteroid treatment (95\% CI 1.29824.57) with OR 5.647 are found to be significantly associated with development of DHF.

Diabetes is a metabolic disorder that reduces the use of glucose by organism and changes the anatomical and physiological integrity of endothelium due to permanent inflammatory condition, which is caused by activation of T-lymphocytes. This process leads to release of pro-inflammatory cytokines such as gamma interferon \& TNF $\alpha$. These cytokines are known to have fundamental role in one of the main phenomena responsible for clinical manifestation of DHF, the third space shift, which is a consequence of endothelial dysfunction and results in hypotension, shock and hemoconcentration. Likewise Hypertension also has detrimental effects on endothelial functions which may help trigger the phenomena of fluid shift resulting from increased vascular permeability that characterizes DHF.

The immune system in allergic individuals may be persistently activated with signs of inflammation in tissues and capillaries. If use of steroid for treatment of allergies is considered especially for severe allergies, then it can be concluded that severe allergy is more likely to lead to inflammation and liberation of pro-inflammatory cytokines in tissues, particularly endothelium.

Use of corticosteroid itself can increase risk of DHF as it increases capillary fragility such in treatments of allergies, asthma etc. Limitation of my study is very small study to assess such factors. (Figueiredo et al. 2010)

Results of this study should be interpreted considering its smaller size, retrospective nature as results are dependent upon quality of data available and collected. There can be selection bias as all patients were hospitalized and health care seeking behavior may be the cause. 
Texila International Journal of Public Health

Volume 4, Issue 4, Dec 2016

During dengue epidemics most patients are seen in outdoor setting and are sent to home because all cannot be hospitalized in spite of risk of developing DHF. These identified risk factors can be used to categories patients for efficient use of resources in monitoring and prevention of DHF.

\section{Summary}

About two-thirds of the world's population lives in areas infested with dengue vectors, mainly Aedesaegypti. All four dengue viruses are circulating, sometimes simultaneously, in most of these areas. It is estimated that up to 80 million persons become infected annually, although marked underreporting results in the notification of much smaller number of cases. Currently dengue is endemic in all continents except Europe and epidemic DHF occurs in Asia and in the Americas. The incidence of DHF is greater by far in Asia than in the Americas.(Drosten et al. 2002)

Risk of Fatal Dengue hemorrhagic Fever is increased with co morbidities like Diabetes A retrospective study conducted about potential risk factors associated with fatal DHF. Descriptive data about the enrolled patients was collected from the Shalamar hospital on a structured questionnaire. Descriptive epidemiology about fatal DHF was described in terms of place, person and time.

The data analysis was done using SPSS v.16 software. Chi-square test was used to determine the relationship between gender, age group, Diabetes, Hypertension, TB Asthma, Allergies, Smoking and Paralysis and outcome of interest. P-value of $<0.05$ is considered statistically significant (Hosmer et al. 2000)

The study identified potential risk factors associated with Fatal Dengue Fever like age to be significantly associated with DHF cases whereas Diabetes and Hypertension were not found to be significantly associated. Limitation of the study is its smaller size and confirmation requires larger scale studies. These finding could be utilized by the health authorities to guide triaging of patients who require closer monitoring and early hospitalization when confirmed in more studies in Lahore.

\section{References}

[1]. Ahmed S, Mohammad W, Hamid F, Akhter A, Afzal RK, Mahmood A.2011. The 2011 dengue haemorrhagic Fever outbreak in lahore-an account of clinical parameters and pattern of haemorrhagic complications. J Coll Physicians Surg Pak. 23 (7): 463-467.

[2]. Chairulfatah A, Setiabudi D, Agoes R, van Sprundel M, Colebunders R. 2001. Hospital based clinical surveillance for dengue haemorrhagic fever in Bandung, Indonesia 1994-1995. Acta tropica. 80 (2): 111-115.

[3]. Deen JL, Harris E, Wills B, Balmaseda A, Hammond SN, Rocha C, Dung NM, Hung NT, Hien TT, Farrar JJ. 2006. The WHO dengue classification and case definitions: time for a reassessment. The Lancet. 368 (9530): 170-173.

[4]. DeRoeck D, Deen J, Clemens JD. 2003. Policymakers' views on dengue fever/dengue haemorrhagic fever and the need for dengue vaccines in four southeast Asian countries. Vaccine. 22 (1): 121-129.

[5]. Drosten C, Göttig S, Schilling S, Asper M, Panning M, Schmitz H, Günther S. 2002. Rapid detection and quantification of RNA of Ebola and Marburg viruses, Lassa virus, Crimean-Congo hemorrhagic fever virus, Rift Valley fever virus, dengue virus, and yellow fever virus by real-time reverse transcription-PCR. J. clin microbiol. 40 (7): 2323-2330.

[6]. Fernandez-Mestre MT, Gendzekhadze K, Rivas-Vetencourt P, Layrisse Z. 2004. TNF-alpha-308 Aallele, a possible severity risk factor of hemorrhagic manifestation in dengue fever patients. Tissue Antigens. 64:469-72

[7]. Figueiredo MAA, Rodrigues LC, Barreto ML, Lima JWO, Costa MC, Morato V, Blanton R, Vasconcelos PF, Nunes MR, Teixeira MG. 2010. Allergies and diabetes as risk factors for dengue hemorrhagic fever: results of a case control study. PLoS neglected tropical diseases. 4 (6): e699. 
[8]. Gibbons RV, Vaughn DW. 2002. Dengue: an escalating problem. BMJ: British Medical Journal. 324 (7353): 1563.

[9]. Gonzalez D, Castro OE, Kouri G, Perez J, Martinez E, Vazquez S, Rosario D, Cancio R, Guzman MG. 2005. Classical dengue hemorrhagic fever resulting from two dengue infections spaced 20 years or more apart: Havana, Dengue 3 epidemic, 2001-2002. Int J Infect Dis. 9 (5): 280-285.

[10]. Gubler DJ 2002. Epidemic dengue/dengue hemorrhagic fever as a public health, social and economic problem in the 21st century. Trends Microbiol. 10 (2): 100-103.

[11]. Guzman MG, Alvarez M, Rodriguez R, Rosario D, Vazquez S, Valdes L, Cabrera MV, Kouri G. 1999. Fatal Dengue Hemorrhagic Fever in Cuba, 1997. IJID. 3 (3): 130-135.

[12]. Halstead S 1980. Dengue haemorrhagic fever—a public health problem and a field for research. Bulletin of the World Health Organization. 58 (1): 1.

[13]. Halstead SB 2007. Dengue. The Lancet. 370 (9599): 1644-1652.

[14]. Humayoun MA, Waseem T, Jawa AA, Hashmi MS, Akram J.2008. Multiple dengue serotypes and high frequency of dengue hemorrhagic fever at two tertiary care hospitals in Lahore during the 2008 dengue virus outbreak in Punjab, Pakistan. Int J Infect Dis. 14 e54-e59.

[15]. Jennifer L. Kyle, Eva Harris. 2008. Global Spread and Persistence of Dengue. Annu. Rev. Microbiol.62:71-92

[16]. Khan MIH, Anwar E, Agha A, Hassanien NSM, Ullah E, Syed IA, Raja A. 2013. Factors Predicting Severe Dengue in Patients with Dengue Fever. Mediterr J Hematol Infect Dis. 5 (1).

[17]. Libraty DH, Young PR, Pickering D, Endy TP, Kalayanarooj S, Green S, Vaughn DW, Nisalak A, Ennis FA, Rothman AL. 2002. High circulating levels of the dengue virus nonstructural protein NS1 early in dengue illness correlate with the development of dengue hemorrhagic fever. J. Infect. Dis. 186 (8): 1165-1168.

[18]. Mahmood K, Jameel T, Aslam HF, Tahir M. 2009. Incidence of dengue haemorrhagic fever in local population of Lahore, Pakistan. Biomedica. 25 93-96.

[19]. Mahmood S, Hafeez S, Nabeel H, Zahra U, Nazeer H. Does Comorbidity Increase the Risk of Dengue Hemorrhagic Fever and Dengue Shock Syndrome? ISRN Tropic Med. 2013.

[20]. Pang J, Salim A, Lee VJ, Hibberd ML, Chia KS, Leo YS, Lye DC. 2012. Diabetes with Hypertension as Risk Factors for Adult Dengue Hemorrhagic Fever in a Predominantly Dengue Serotype 2 Epidemic: A Case Control Study. PLoS Negl Trop Dis. 6 (5): e1641.

[21]. Pinheiro FP, Corber SJ. 1997. Global situation of dengue and dengue haemorrhagic fever, and its emergence in the Americas. World Health Stat Q. 50 161-169.

[22]. Shahzad MK, Ijaz T, Ijaz S, Younus M. 2007. Lab Based surveillance of Dengue Hemorrhagic Fever during 2006 Epidemic in Lahore. Int J Agro Vet Med Sci. 1 (0): 13-16.

[23]. Wahid S, Sanusi S, Zawawi MM, Ali RA. 2000. A comparison of the pattern of liver involvement in dengue hemorrhagic fever with classic dengue fever. 